\title{
BMJ Open Urine cytology screening of French workers exposed to occupational urinary tract carcinogens: a prospective cohort study over a 20 -year period
}

\author{
Frederic Dutheil, ${ }^{1,2}$ Lucile Rouanet, ${ }^{3}$ Aurélien Mulliez, ${ }^{4}$ Geraldine Naughton, \\ Luc Fontana, ${ }^{5,6,7}$ Michel Druet-Cabanac, ${ }^{8}$ Farès Moustafa, ${ }^{9}$ Alain Chamoux ${ }^{3}$
}

To cite: Dutheil F, Rouanet L, Mulliez A, et al. Urine cytology screening of French workers exposed to occupational urinary tract carcinogens: a prospective cohort study over a 20-year period. BMJ Open 2017;7:e016238. doi:10.1136/ bmjopen-2017-016238

- Prepublication history for this paper is available online. To view these files please visit the journal online (http://dx.doi org/10.1136/bmjopen-2017016238).

FD and LR contributed equally.

Received 1 February 2017 Revised 30 May 2017

Accepted 10 July 2017

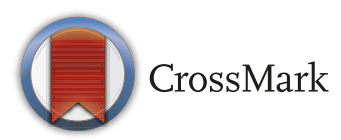

For numbered affiliations see end of article.

Correspondence to Dr Frederic Dutheil; fred_dutheil@yahoo.fr

\section{ABSTRACT}

Objectives To demonstrate that urine cytology screening can provide relevant epidemiological data for earlier detection of urothelial cancer caused by occupational exposure.

Design Prospective cohort study.

Setting Industries using urothelial carcinogens in France. Urine samples were collected on site, after a work week and were analysed at the University Hospital of Clermont-Ferrand, France.

Participants Participants were workers exposed to urothelial carcinogens. Women and current smokers at time of study recruitment were exclusion criteria.

Outcomes Urine cells atypia were ranged into three classes: negative/normal, atypical/suspicious/ dysplasia or positive/malignant.

Results We included 2020 workers over a period of 20 years from 1993 to 2013: 606 worked in rubber manufacturing, 692 from metal processing, 245 in chemical industry and 477 in roadwork and building industry. Workers had a mean exposure of $15.2 \pm 10.4$ years before their first urine cytology screening. There was a mean of $3.4 \pm 4.3$ urine cytology screenings per worker between 1993 and 2013. 6478 cytology were normal, 462 suspicious and 13 malignant. Suspicious and malignant cytology occurred in $4.8 \%$ of workers exposed for $1-10$ years, $6.2 \%$ for $11-20$ years of exposure, $7.6 \%$ for $21-30$ years and $8.6 \%$ for $>30$ years $(p<0.001)$. Using exposure for $1-10$ years as reference, the adjusted $\mathrm{OR}$ of receiving a suspicious or malignant diagnosis increased with duration of exposure: $0 \mathrm{R}=1.50(95 \% \mathrm{Cl} 1.10$ to $2.05, \mathrm{p}=0.01)$ for $21-30$ years and $\mathrm{OR}=1.78(95 \% \mathrm{Cl} 1.23$ to 2.56 , $p=0.002$ ) for $>30$ years of exposure. Using metal processing as reference, the risk of pathological urine cytology results increased for rubber manufacturing $(\mathrm{OR}=1.32,95 \% \mathrm{Cl} 1.05$ to $1.65, \mathrm{p}=0.02)$, with a trend for roadwork and building industry $(0 \mathrm{R}=1.39,95 \% \mathrm{Cl}$ 0.98 to $1.97, p=0.07)$ and for chemical industry $(0 \mathrm{R}=1.34,95 \% \mathrm{Cl} 0.94$ to $1.93, \mathrm{p}=0.11)$.

Conclusions Urine cytology is a useful tool in occupational medicine. We promote new guidelines with an early screening of urothelial cancer by cytology, starting with beginning of exposure.
Strengths and limitations of this study

- We analysed a large-scale sample size of workers over a 20-year period.

- Our rigorous inclusion criteria avoided potential bias.

- We did not have final diagnosis or an eventual occupational disease recognition.

\section{INTRODUCTION}

Urinary tract cancers are a public health problem. With 11965 new cases in 2012 in France and 386000 worldwide in 2008, urothelial bladder cancer is the seventh cancer worldwide. ${ }^{12}$ In France, urothelial bladder cancer is the fifth most common cancer in men. ${ }^{3}$ More generally, occupational exposure is a major cause of urinary tract cancer including kidney and bladder cancer. ${ }^{45}$ Among potential urothelial carcinogens existing, three classes are recognised: aromatic amines, ${ }^{6-10}$ polycyclic aromatic hydrocarbons ${ }^{7} 11$ and nitrosamines. ${ }^{2} 8$ 11-13 These carcinogens are mainly used in rubber manufacturing, 710 13-15 chemical industry, ${ }^{6}{ }^{15}$ roadwork industry ${ }^{13}$ and metal processing. ${ }^{13}$ 16-19

Besides tobacco consumption, the proportion of urothelial cancer due to occupational exposure ranges from $5 \%$ to $25 \% .^{22021}$ In France, this proportion is largely underestimated: claims for recognition of occupational diseases are few. ${ }^{322}$ This is partly due to the very long latency between the first exposition and the diagnosis, from 14 to 26 years and rarely before 20 years. $^{2} 22$ The frequency and latency of urinary tract cancers offered a potential for large-scale screening in workers exposed to urothelial occupational carcinogens. Prognosis of urinary tract cancers is better when a diagnosis is made at an early stage. ${ }^{23}$ Earlier diagnosis is needed for survival improvement, in conjunction with aggressive radical surgery in intention 
to cure (cystectomy) and/or adjuvant multimodal treatment (radiotherapy and chemotherapy) ${ }^{24}$ However, early stages are rarely detected, because clinical symptoms occur late in the evolution of the disease. Thus, screening during an early stage of urinary tract cancers appears salient. Actually, screening is based on urine cytology also called Papanicolaou cytology. Individuals with a positive cytology need a cystoscopy to make positive diagnosis. Whatever tumours' grades and stages, urine cytology has a high specificity up to $90 \%$. Sensitivity increases with severity of tumours, reaching excellent values for highgrade tumours requiring urgent medical care. ${ }^{225-28}$

To the best of our knowledge, no studies provided results of large-scale screening for urothelial cancers in workers over consecutive decades. Despite duration of exposure increases incidence of urothelial cancers, ${ }^{2}$ no studies showed dose-response relationship based on a huge number of urine cytology. There are also no studies comparing urine cytology anomalies in main occupational sectors. Although the introduction of measures protecting workers over the last decades, ${ }^{2} 121729-33$ urothelial cancer remains frequent. There are several studies on amelioration of industrial hygiene and bladder cancer, but none or very few concerning all the urinary tract cancer.

Therefore, our hypothesis would be that (1) there are dose-response relationships-anomalies would increase with the duration of exposure; (2) urine cytology would differentiate at-risk occupational sectors such as rubber manufacturing, chemical industry, roadwork and building industry and metalworking; (3) urine cytology would demonstrate industrial hygiene improvements.

The aim of this study is to demonstrate that urine cytology screening can provide relevant epidemiological data for earlier detection of urothelial cancer caused by occupational exposure to urinary tract carcinogens, using a large-scale sample size of workers over a 20-year period.

\section{METHODS}

\section{Participants}

Participants were workers potentially exposed to urinary tract occupational carcinogens, in France and mainly in the Auvergne region. Follow-up was assessed by their occupational physician. Their occupational physician recorded sociodemographic and occupational data such as gender, birthdate, occupational sector, date of first and last occupational exposure and thus the duration of exposure. Occupational exposure could have started any time prior to the first screening provided by physicians (ie, before the beginning of the follow-up). Women and current smokers at time of study were excluded. We included 2020 workers over a period of 20 years, from 1993 to 2013. All included participants were men and non-smokers. Occupational sectors were rubber manufacturing for 606 workers, metal processing for 692 workers, chemical industry for 245 workers and roadwork and building industry for
477 workers. All rubber manufacturing workers were employed in the tyre sector. Metal processing workers included those within metalworking fluid and foundries. The chemical industry workers mainly included pharmaceutical manufacturers, who worked with dyes, adhesives or synthetic resins or in biological laboratories. Workers from roadwork and building industry were mainly exposed to asphalt and bitumen. The ethics committee from the University Hospital of Clermont-Ferrand (CHU), France, concluded that there was no need for ethics approval when data collected for secondary analyses were unidentifiable and part of daily clinical practice $(2015 \mathrm{CE} / 101)$. Therefore, workers did not provide consent.

\section{Urine collection and analysis}

Urine samples were collected on site, after several consecutive days of work. Urine samples were sent by post in refrigerated packages to the Center of Occupational Diseases of the University Hospital of Clermont-Ferrand (CHU), France. Urine samples were analysed within the 24 hours after receipt date. High dysplasia and malignancy results were communicated directly to the occupational physician of workers for possible further investigations.

\section{Outcomes: urine cytology classes}

Based on Papanicolaou method, urine cells atypia were categorised in three classes ${ }^{345}$ :

- Negative/normal: urothelial cells, sometimes irritative signs, no atypical or malignant signs.

- Atypical/suspicious/dysplasia: the cytological features were similar to those of malignancy but with a lesser degree. Nuclear enlargement was less prominent and nuclear cytoplasmic $(\mathrm{N} / \mathrm{C})$ ratios less disturbed.

- Positive/malignant: the cells showed features of highgrade malignancy and were arranged both singly and in small, relatively flat sheets of up to 15 cells. Cell size was same or slightly larger than intermediate transitional cells with a shape round or polygonal, occasionally irregularly elongated. Nuclei were irregular in shape, notched or pointed. They were either vesicular or structureless. Nuclei were more than one and a half the size of normal nuclei with abnormal $\mathrm{N} / \mathrm{C}$ ratios. Chromatin was black and structureless or coarse granular. Occasional cells contained multiple malignant nuclei. Nucleoli were generally absent or not prominent.

\section{Statistics}

Statistics were computed with Stata V.13. Data are expressed as frequencies and associated percentages for categorical variables and as mean $\pm \mathrm{SD}$ and range or as median and IQR for quantitative parameters.

Univariate analysis of suspicious and malignant cytology was performed to test statistical relationships with age, duration of exposure, years of exposure, using $\chi^{2}$ trend test and using $\chi^{2}$ test when comparing with occupational sector. Multivariate analyses involved logistic regression, 
adjusting for all these parameters. The odds ratio (OR) was calculated by dividing the odds of suspicious/malignant cytologies versus the odds of normal cytologies. Results are showed as OR with their 95\% CI. All tests were two-sided and a $p$ value $<0.05$ was considered significant. For the age of workers, duration of exposure and years of exposure, data were both analysed as continuous variables or categorical. Categories were defined from exploratory analyses.

\section{RESULTS}

\section{Outcomes: urine cytology}

Workers had a mean exposure of $15.2 \pm 10.4$ years before their first urine cytology screening. There was a mean of $3.4 \pm 4.3$ urine cytology screenings per worker between 1993 and 2013. There were 6478 tests with normal cytology, 462 with dysplasia and 13 with malignant results. Therefore, 13 tests $(0.19 \%)$ had criteria of urothelial cancer out of 6953 tests.

\section{Dose-response relationship}

There is a global dose-response relationship between duration of exposure and urine cytology classes. Suspicious and malignant cytology accounted for $4.8 \%$ of workers exposed for 1-10 years, $6.2 \%$ for 11-20 years of exposure, $7.6 \%$ for $21-30$ years and $8.6 \%$ for $>30$ years $(\mathrm{p}<0.001)$. Similarly, the severity of urine cytology classes increased with duration of exposure, comparing to an exposition of 1 to 10 years, within each occupational sectors: rubber manufacturing $(4.3 \%, 7.5 \%, 9.1 \%$ and $7.6 \%$ of suspicious and malignant cytology for exposures of 1-10, 11-20, 21-30 and >30 years, respectively, $\mathrm{p}=0.005)$, metal processing $(4.9 \%, 4.4 \%, 5.1 \%$ and $9 \%$ for exposures of 1-10, 11-20, 21-30 and >30 years, respectively, $\mathrm{p}=0.004)$, with a trend for chemical industry $(5.4 \%$, $5.3 \%, 9.1 \%$ and $9.3 \%$ for exposures of $1-10,11-20,21-30$ and $>30$ years, respectively, $\mathrm{p}=0.11$ ) and roadwork and building industry $(4.9 \%, 6.1 \%, 8 \%$ and $10.1 \%$ for exposures of $1-10,11-20,21-30$ and $>30$ years, respectively, $\mathrm{p}=0.06$ ) (table 1 and figure 1 ).

Results were confirmed by multivariate analysis. With increasing duration of exposure the risk of showing a suspicious and malignant cytology increased linearly $(\mathrm{OR}=1.02,95 \% \mathrm{CI} 1.01$ to $1.03, \mathrm{p}<0.001)$ in the overall analysis, but only statistically significant in stratified analysis for workers from rubber manufacturing $(\mathrm{OR}=1.03$, 95\% CI 1.01 to $1.04, \mathrm{p}<0.001$ ) (table 2). Similar significant results were found using duration of exposure as a categorical variable (1-10, 11-20, 21-30 and >30 years). Using exposure during 1 to 10 years for comparative purposes, the odds of receiving a suspicious or malignant diagnosis compared with a normal cytology was globally higher when duration of exposure increased: $\mathrm{OR}=1.50$ for $21-30$ years of exposure $(95 \%$ CI 1.10 to 2.05, $\mathrm{p}=0.01$ ) and $\mathrm{OR}=1.78$ for $>30$ years of exposure (95\% CI 1.23 to $2.56, \mathrm{p}=0.002)$. Results were similar

Table 1 Urine cytology classes and duration of exposure

\begin{tabular}{|c|c|c|c|c|c|}
\hline & & Negative & Suspicious & Malignant & p Value \\
\hline \multirow{2}{*}{$\begin{array}{l}\text { All occupational } \\
\text { sectors }\end{array}$} & 11-20years, n (\%) & 1477 (93.8) & $96(6.1)$ & $2(0.1)$ & \multirow{2}{*}{0.001} \\
\hline & $>30$ years, $n(\%)$ & 1039 (91.5) & $95(8.4)$ & $2(0.2)$ & \\
\hline \multirow[t]{3}{*}{ Rubber manufacturing } & 1-10years, n (\%) & $557(95.7)$ & $23(4.0)$ & $2(0.3)$ & \multirow[t]{3}{*}{0.005} \\
\hline & 21-30years, n (\%) & $1300(90.9)$ & $126(8.8)$ & $4(0.3)$ & \\
\hline & >30years, n (\%) & $380(92.5)$ & $29(7.1)$ & $2(0.5)$ & \\
\hline \multirow[t]{2}{*}{ Metal processing } & $1-10$ years, n (\%) & 355 (95.2) & $17(4.6)$ & $1(0.3)$ & \multirow[t]{2}{*}{0.004} \\
\hline & 11-20years, n (\%) & $436(95.6)$ & $20(4.4)$ & $0(0)$ & \\
\hline \multirow{3}{*}{ Chemical industry } & 11-20years, n (\%) & $143(94.7)$ & $8(5.3)$ & $0(0)$ & \multirow{3}{*}{0.110} \\
\hline & 21-30years, n (\%) & $150(90.9)$ & $15(9.1)$ & $0(0)$ & \\
\hline & >30years, n (\%) & $49(90.7)$ & $5(9.3)$ & $0(0)$ & \\
\hline \multirow{4}{*}{$\begin{array}{l}\text { Roadwork/building } \\
\text { industry }\end{array}$} & $1-10$ years, n (\%) & $290(95.1)$ & $15(4.9)$ & $0(0)$ & \multirow[t]{4}{*}{0.060} \\
\hline & 11-20years, n (\%) & $213(93.8)$ & $13(5.7)$ & $1(0.4)$ & \\
\hline & 21-30years, n (\%) & $172(92.0)$ & $15(8.0)$ & $0(0)$ & \\
\hline & >30years, n (\%) & $62(89.9)$ & $7(10.1)$ & $0(0)$ & \\
\hline
\end{tabular}

$p$ values from $\chi^{2}$ tests. 
All occupational sectors

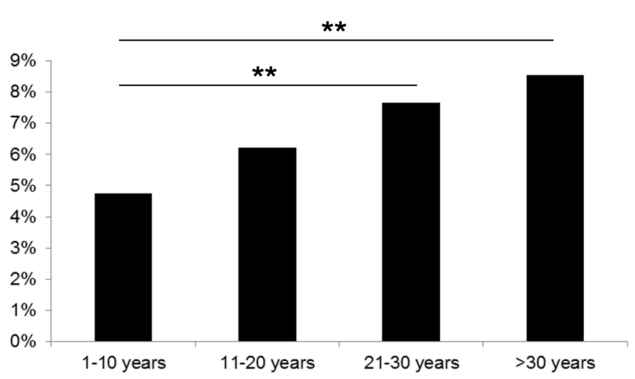

Metal processing

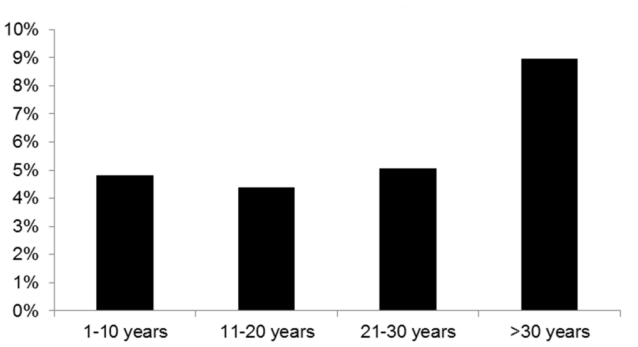

Roadwork/builiding

industry

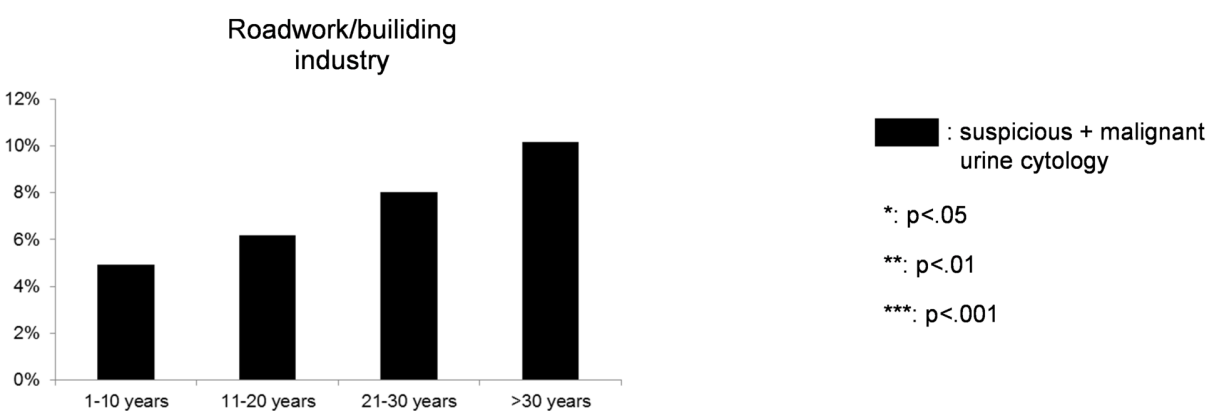

Rubber manufacturing

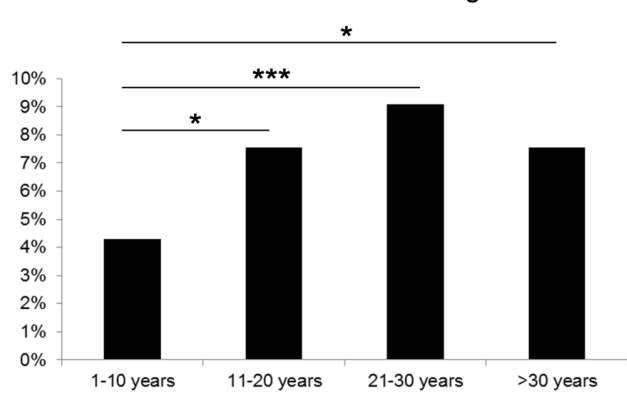

Chemical industry

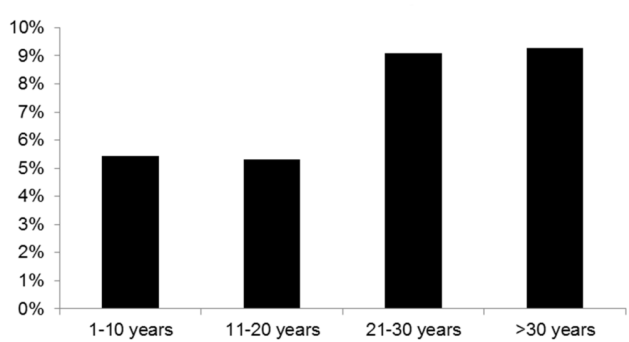

Figure 1 Percentage of abnormal urine cytology (suspicious+malignant) and duration of exposure.

for rubber manufacturing: $\mathrm{OR}=1.79$ for $11-20$ years of exposure $(95 \%$ CI 1.09 to $2.93, \mathrm{p}=0.02), \mathrm{OR}=2.24$ for 21-30 years of exposure $(95 \%$ CI 1.39 to $3.59, \mathrm{p}=0.001)$ and $\mathrm{OR}=1.99$ for $>30$ years of exposure $(95 \%$ CI 1.11 to $3.57, \mathrm{p}=0.02)$. Results were also not significant for metal processing chemical industry and for roadwork and building industry (table 3 ).

\section{Suspicious and malignant cytology and occupational sectors}

Considering metal processing as reference with continuous variables for age, duration of exposure and years of exposure, the risk of pathological urine cytology results increased for rubber manufacturing $(\mathrm{OR}=1.3,95 \% \mathrm{CI} 1.04$ to 1.63 , $\mathrm{p}=0.02)$ and for roadwork and building industry $(\mathrm{OR}=1.42$, $95 \%$ CI 1.00 to 2.01, p=0.05) (table 2 ). With categorised variables, results are similar for rubber manufacturing $(\mathrm{OR}=1.32$, $95 \%$ CI 1.05 to $1.65, \mathrm{p}=0.02$ ), with a trend for roadwork and building industry $(\mathrm{OR}=1.39,95 \%$ CI 0.98 to $1.97, \mathrm{p}=0.07)$ and for chemical industry $(\mathrm{OR}=1.47,95 \% \mathrm{CI} 0.94$ to 1.93 , $\mathrm{p}=0.11$ ) (table 3 and figure 2).

\section{Pathological urine cytology and age}

With increasing age the risk of showing a suspicious and malignant cytology increased linearly (OR=1.02, 95\% CI 1.00 to $1.04, \mathrm{p}=0.03$ ) in the overall analysis, but only statistically significant in stratified analysis for workers from chemical industry $(\mathrm{OR}=1.05,95 \% \mathrm{CI} 1.01$ to $1.10, \mathrm{p}=0.02)$ (table 2). Similarly, workers aged over 50 years old had a greater risk of suspicious and malignant cytology diagnoses for chemical industry $(\mathrm{OR}=4.40,95 \% \mathrm{CI} 1.59$ to 12.14, $\mathrm{p}=0.004)$, with also a global trend $(\mathrm{OR}=1.38$, $95 \%$ CI 0.95 to $2.00, \mathrm{p}=0.09)$. Results were not significant for other occupational sectors (table 3 ).

\section{Pathological urine cytology and industrial hygiene improvements}

The risk of showing a suspicious and malignant cytology decreased linearly with more recent years of exposure ( $\mathrm{OR}=0.97,95 \% \mathrm{CI} 0.96$ to $0.99, \mathrm{p}=0.01$ ) in the overall analysis, but only statistically significant in stratified analysis for workers from rubber manufacturing ( $\mathrm{OR}=0.97$, $95 \%$ CI 0.94 to $0.99, \mathrm{p}=0.02$ ) (table 2 ). Similar significant 
Table 2 Multivariate analyses of risk for urine cytology anomalies in relations with occupational sectors and dose-response relationships by analysing the variables continuously

\begin{tabular}{|c|c|c|c|c|}
\hline & Continuous variables* & OR & $95 \% \mathrm{Cl}$ & p Value \\
\hline \multicolumn{5}{|l|}{ All occupational sectors } \\
\hline Duration of exposure & & 1.02 & 1.01 to 1.03 & $<0.001$ \\
\hline Age & & 1.02 & 1.00 to 1.04 & 0.030 \\
\hline \multirow[t]{4}{*}{ Occupational sector } & Metal processing & Reference & & \\
\hline & Rubber manufacturing & 1.30 & 1.04 to 1.63 & 0.020 \\
\hline & Chemical industry & 1.37 & 0.95 to 1.96 & 0.090 \\
\hline & Roadwork and building industry & 1.42 & 1.00 to 2.01 & 0.050 \\
\hline Years of exposure & & 0.97 & 0.96 to 0.99 & 0.010 \\
\hline \multicolumn{5}{|l|}{ Rubber manufacturing } \\
\hline & Duration of exposure & 1.03 & 1.01 to 1.04 & $<0.001$ \\
\hline & Age & 1.00 & 0.97 to 1.02 & 0.800 \\
\hline & Years of exposure & 0.97 & 0.94 to 0.99 & 0.020 \\
\hline \multicolumn{5}{|l|}{ Metal processing } \\
\hline & Duration of exposure & 1.02 & 0.99 to 1.04 & 0.140 \\
\hline & Age & 1.03 & 0.99 to 1.06 & 0.130 \\
\hline & Years of exposure & 0.98 & 0.95 to 1.02 & 0.270 \\
\hline \multicolumn{5}{|l|}{ Chemical industry } \\
\hline & Duration of exposure & 1.01 & 0.98 to 1.04 & 0.680 \\
\hline & Age & 1.05 & 1.01 to 1.10 & 0.020 \\
\hline & Years of exposure & 1.00 & 0.94 to 1.06 & 0.890 \\
\hline \multicolumn{5}{|c|}{ Roadwork and building industry } \\
\hline & Duration of exposure & 1.02 & 0.98 to 1.06 & 0.330 \\
\hline & Age & 1.03 & 0.99 to 1.07 & 0.180 \\
\hline & Years of exposure & 0.97 & 0.92 to 1.01 & 0.150 \\
\hline
\end{tabular}

Significant results $(p<0.05)$ are highlighted in bold.

*Except for occupational sector.

results were found using years of exposure as a categorical variable. Suspicious and malignant cytology diagnoses globally decreased between 1993 and 2013. Using the 1993-1997 period for comparative purposes, OR=0.73 for the $1998-2002$ period, (95\% CI 0.58 to $0.92, \mathrm{p}=0.006)$, $\mathrm{OR}=0.72$ for $2003-2007$ (95\% CI 0.54 to $0.96, \mathrm{p}=0.02$ ), $\mathrm{OR}=0.67$ for $2007-2013$ (95\% CI 0.49 to $0.91, \mathrm{p}=0.01$ ). Results were similar for metal processing: $\mathrm{OR}=0.55$ for $1998-2002$ (95\% CI 0.35 to $0.86, \mathrm{p}=0.01)$ and $\mathrm{OR}=0.51$ for 2007-2013 (95\% CI 0.28 to $0.93, \mathrm{p}=0.03$ ); for roadwork and building industry: OR=0.41 for $1998-2002(95 \%$ CI 017 to 0.98, $\mathrm{p}=0.04$ ) and $\mathrm{OR}=0.30$ for $2003-2007$ (95\% CI 0.09 to $0.95, \mathrm{p}=0.04$ ) and for rubber manufacturing: $\mathrm{OR}=0.62$ for 2003-2007 (95\% CI 0.40 to $0.97, \mathrm{p}=0.04$ ). Results were not significant for chemical industry (table 3 ).

\section{DISCUSSION}

The major findings of this study were that urine cytology screening can provide relevant epidemiological data for earlier detection of urothelial cancer caused by occupational exposure to urinary tract carcinogens, using a large-scale sample size of workers over a 20-year period. Specifically, we demonstrated that anomalies on urine cytology followed a dose-response relationship. Occupational sectors with an increased risk were rubber manufacturing, roadwork and building industry. Furthermore, industrial hygiene improvements permitted a reduction of anomalies on cytology.

Urine cytology and occupational exposure: effectiveness and dose-response relationship

We reported a large sample of workers involved in a long-term follow-up of urinary tract occupational exposure with urine cytology. Previous literature generally completed investigations by cystoscopic examinations $^{25}{ }^{26}$ or compared different screening procedures. ${ }^{25} 2628$ However, we demonstrated that urine cytology was a reliable tool to assess occupational exposure to urinary tract carcinogens and provided relevant epidemiological data. As expected and showed for other carcinogens, age is a risk factor of cancer. ${ }^{36}$ Indeed in the majority of cases, urothelial tumours appear after 
Table 3 Multivariate analyses of risk for urine cytology anomalies in relations with occupational sectors and duration of exposure, age and years of exposure as categorical variables

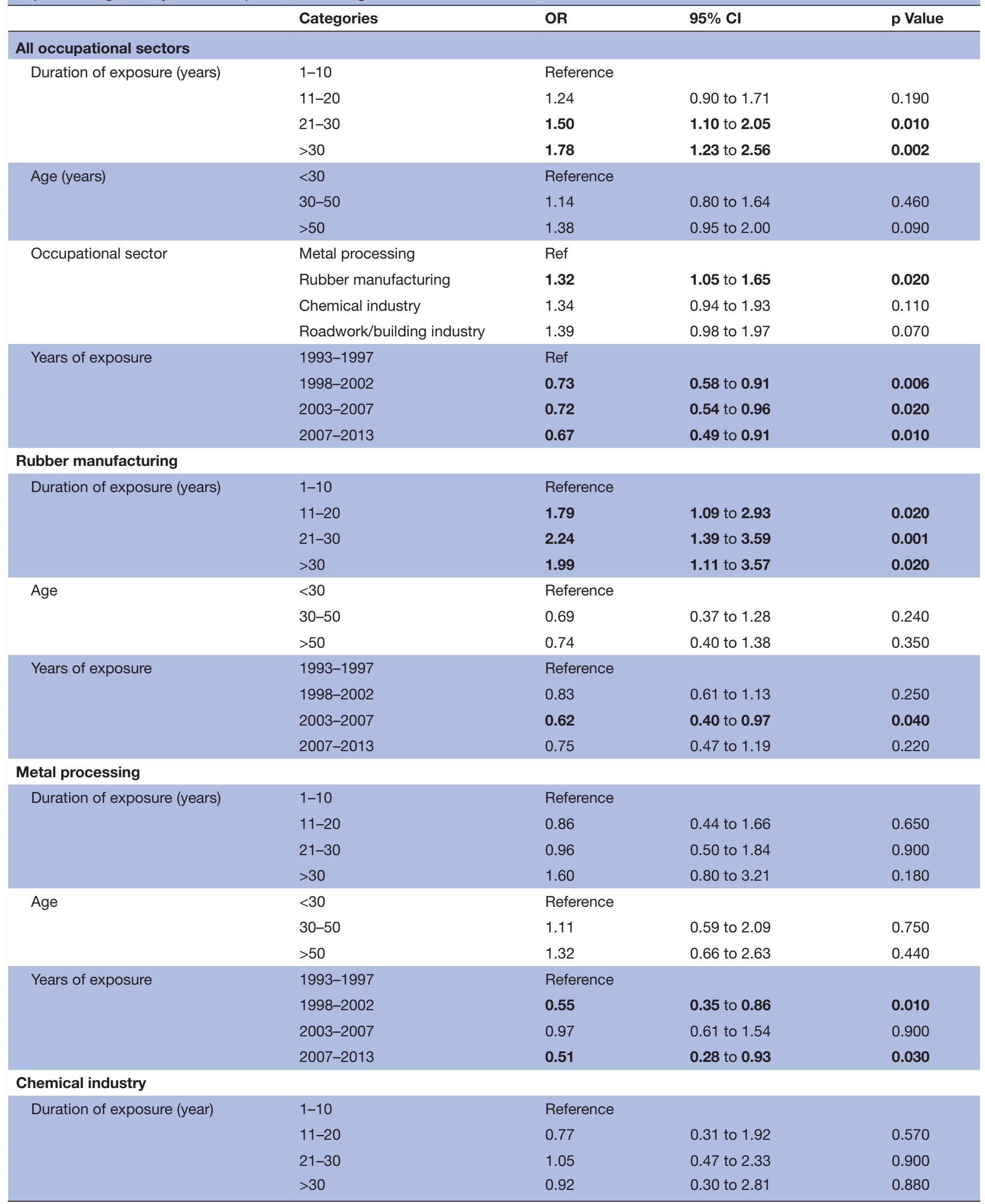


Table 3 Continued

\begin{tabular}{|c|c|c|c|c|}
\hline & Categories & OR & $95 \% \mathrm{Cl}$ & p Value \\
\hline \multirow[t]{2}{*}{ Age } & $<30$ & Reference & & \\
\hline & $30-50$ & 2.02 & 0.72 to 5.66 & 0.180 \\
\hline \multirow[t]{2}{*}{ Years of exposure } & 1993-1997 & Reference & & \\
\hline & 1998-2002 & 1.40 & 0.66 to 2.99 & 0.390 \\
\hline \multicolumn{5}{|l|}{ Roadwork/building industry } \\
\hline \multirow[t]{3}{*}{ Duration of exposure (years) } & $1-10$ & Reference & & \\
\hline & $11-20$ & 0.92 & 0.41 to 2.09 & 0.840 \\
\hline & $21-30$ & 1.14 & 0.47 to 2.78 & 0.770 \\
\hline Age (years) & $>50$ & 1.62 & 0.64 to 4.12 & 0.310 \\
\hline \multirow[t]{4}{*}{ Years of exposure } & 1993-1997 & Reference & & \\
\hline & 1998-2002 & 0.41 & 0.17 to 0.98 & 0.040 \\
\hline & 2003-2007 & 0.30 & 0.09 to 0.95 & 0.040 \\
\hline & 2007-2013 & 0.55 & 0.27 to 1.12 & 0.100 \\
\hline
\end{tabular}

Significant results $(p<0.05)$ are highlighted in bold.

the age of 60 years. ${ }^{36} 37$ Participants older than 50 were more likely to have a malignant or suspicious cytology. We further found a globally increased RR of receiving a suspicious or malignant diagnosis with duration of exposure, in agreement with recommendations to screen workers exposed to urothelial carcinogens 20 years after the beginning of occupational exposure. ${ }^{2}$ However, the dose-response relationship appeared significant from 10 years of exposure, especially for rubber manufacturing. Moreover, from experience, we noted that early screening was associated with best prognosis and industrial hygiene improvements. Therefore, we strengthen the evidence for new guidelines supporting an early screening of urinary tract cancer, starting from the beginning of occupational exposures. Because of the high latency period between exposure and cancer, and because the significant relationship between age and the risk of abnormal urine cytology, we propose to extend screening beyond retirement (postprofessional follow-up). Both strategies should be

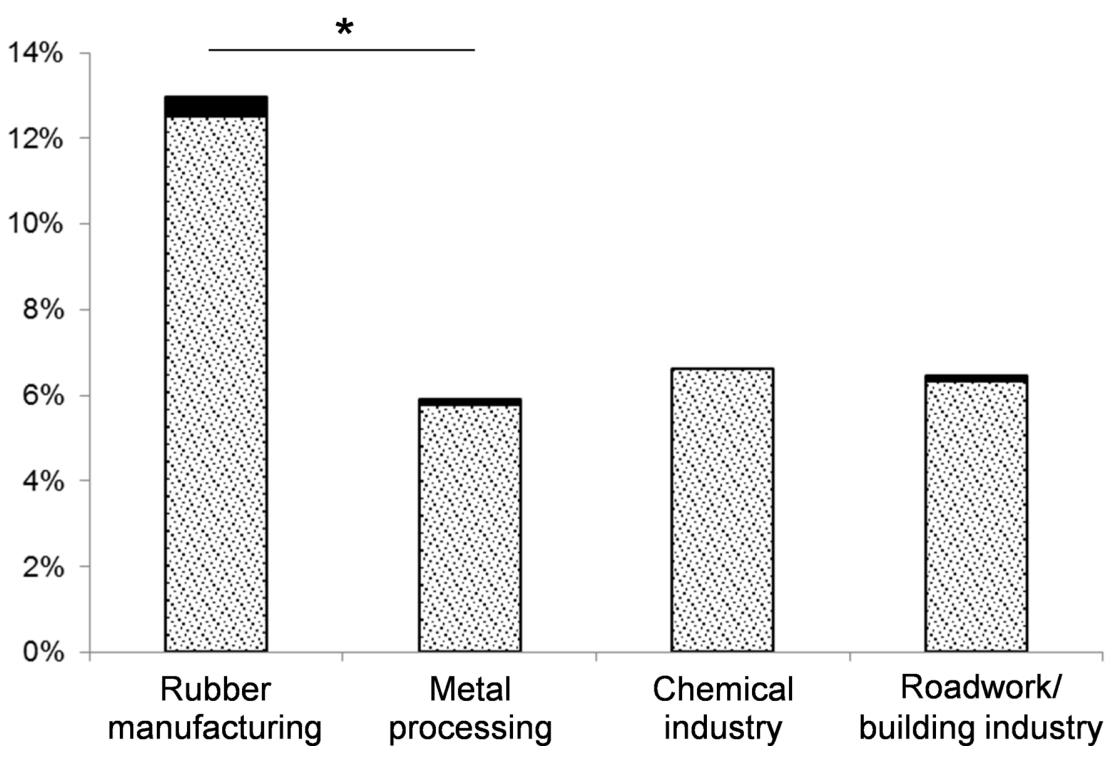

- Malignant

๑ Suspicious

Figure 2 Percentage of suspicious and malignant cytology in each occupational sector. ${ }^{*} \mathrm{p}<0.05$. 
further evaluated, including the best interval between two consecutive urine cytology screenings.

\section{Occupational sectors}

Among potential urothelial carcinogens existing, three classes were recognised: aromatic amines ${ }^{6}$ (such as benzidine,${ }^{7}$ aniline, o-tolidine, o-toluidine, ${ }^{8}{ }^{9} 10$ beta naphtylamine ${ }^{7}$ ), polycyclic aromatic hydrocarbons (such as benzene, ${ }^{12} 1338$ benz(a) pyrene ${ }^{11}$ ) and nitrosamines (such as nitrobenzene ${ }^{8}$ ). They were used in various occupational sectors such as rubber manufacturing, ${ }^{7} 10$ 13-15 chemical and pharmaceutical industry, ${ }^{7}$ dye manufacturing, ${ }^{6} 715$ textile, ${ }^{15}$ plastic, leather and tanning industry, roadwork industry, ${ }^{13}$ metalworkers ${ }^{16}$ metalworking fluids, ${ }^{1718}$ aluminium,,${ }^{19}$ foundries. ${ }^{13}{ }^{19}$ Recommendations for medical follow-up of workers exposed to urinary tract carcinogens classified occupational sectors in four levels of risk, from low to very high. Very highrisk occupational sectors were rubber manufacturing and dye manufacturing. High-risk occupational sectors were aluminium production, textile industry, leather and tanning industry, plastics industry using chloroaniline and production of 4-chloro-ortho-toluidine-based pesticides. Occupational sectors with a moderate risk were chemical and pharmaceutical industry, iron and steel foundries, metalworking. ${ }^{2}$ Therefore, our study confirmed the increased risk of urothelial cancer for those working in the rubber manufacturing ${ }^{215}$ which combines several urinary tract carcinogens such as o-toluidine, aniline and nitrobenzene. ${ }^{8}$ However, we also demonstrated the highest increased risk for roadwork and building industry which is not recognised by the current recommendations. ${ }^{2}$ Thus, we also promote to screen roadwork and building industry workers with urine cytology.

\section{Industrial hygiene improvements}

Since the first occupational bladder cancer discovered in 1895 in a German dye factory manufacturing fuchsin, ${ }^{31} 32$ advances had been made concerning industrial hygiene. In 1974, the Occupational Safety and Health Administration promulgated a standard to control the production and use of benzidine. ${ }^{31}$ In Great Britain, beta-naphtylamine were removed in $1949 .{ }^{33}$ In France, three aromatic amines (benzidine, beta-naphtylamine, 4-amino-biphenyle) were prohibited in 1989. A decrease of the incidence after introduction of measures protecting workers (substitution, modification of process, protection equipment) was observed. ${ }^{29}{ }^{30}$ We confirmed those industrial hygiene improvements, especially in metal processing, roadwork and building industry. Nevertheless, addressing issues of industrial hygiene is still a public health concern at work. ${ }^{12} 17$ For example, aromatic amines were prohibited in France, but many other carcinogens still persist such as $o$-tolidine, $o$-toluidine, $o$-anisidine, chloroaniline (4,4-methylenebis(2-chloroaniline)), and secondary amines reacting with nitrosamines. ${ }^{2}$

\section{Limitations}

There are a number of limitations to this study. Diversified occupational exposure to various potential carcinogens may appear as a limitation, but our classification provided significant insight into occupational sectors and should not preclude generalisability. Moreover, we did not assess other urothelial cancer risk factors. However, we included the main risk factors that account for more than $80 \%$ of urothelial cancer. ${ }^{39}$ There were only a few case with malignant cytology, nevertheless the huge sample size of workers allowed an adequate statistical power to support the primary hypothesis. Despite we did not include women and smokers, our rigorous inclusion criteria avoided potential bias. The 1990s could appear recent regarding improvements in occupational hygiene, though the 20-year period of screening provided informative data for public health management at work. We emphasise the lack of reference test and limitations of urine cytology. Although different techniques were reported to enhance sensitivity and specificity in detection of urothelial tumours such as UroVision, immunocytochemistry or markers as NMP22, their high cost and poor availability are not compatible with a first grade screening. ${ }^{2} 262840$ Moreover, the use of a single screening tool, that is, urine cytology permitted comparisons over time. We did not have final diagnosis or a possible occupational disease recognition. However, our study may contribute to an earlier detection of occupational urothelial cancer and might improve primary prevention at workplaces. ${ }^{2}{ }^{41}$ Giving the low cost of urine cytology and the absence of data collection risks (non-irradiant, non-invasive, painless, easy to collect and easy to measure), cost-effective studies should demonstrate its benefits. The number of cases saved from urothelial cancer death because of abnormal urine cytology should also be further investigated. Despite the significant relationship between age and the risk of abnormal cytology, the absence of results beyond retirement may have underestimated the effects of age, giving the latency of the disease. Screening after retirement should be further evaluated.

\section{CONCLUSIONS}

Urine cytology screening can provide relevant epidemiological data for earlier detection of urothelial cancer caused by to occupational exposure to urinary tract carcinogens. Occupational sectors with an increased risk of urothelial cancer are rubber manufacturing, roadwork and building industry. Relative risk of receiving a suspicious or malignant diagnosis increased with duration of exposure, in agreement with recommendations to screen workers exposed to urothelial carcinogens 20 years after the beginning of occupational exposure. However, we demonstrated a significant linear dose-response relationship between duration of exposure and detection of a suspicious or malignant cytology. As early screening was associated with best prognosis and industrial hygiene improvements, we strengthen the evidence to support 
new guidelines for an early screening of urinary tract cancer by urine cytology screening, starting with initial exposure, reassessed during years of working life and extended after retirement (postprofessional follow-up).

\section{Author affiliations}

${ }^{1}$ Université Clermont Auvergne, CNRS, LaPSCo, Physiological and Psychosocial Stress, University Hospital of Clermont-Ferrand, CHU Clermont-Ferrand, Preventive and Occupational Medicine, Clermont-Ferrand, France

${ }^{2}$ Faculty of Health, Australian Catholic University, Melbourne, Victoria, Australia ${ }^{3}$ Department of Preventive and Occupational Medicine, University Hospital of Clermont-Ferrand, CHU-Clermont-Ferrand, Clermont-Ferrand, France ${ }^{4}$ Clinical Research Direction, University Hospital of Clermont-Ferrand (CHU), Clermont-Ferrand, France

${ }^{5}$ Faculty of Medicine Jacques-Lisfranc, University Jean-Monnet, Saint-Etienne, France

${ }^{6}$ Department of Preventive and Occupational Medicine, University Hospital of SaintEtienne, CHU Saint-Etienne, Saint-Etienne, France

${ }^{7}$ UMR T9405, UMRESTTE (IFSTTAR-UCBL), University Lyon 1, Domaine Rockefeller, Lyon, France

${ }^{8}$ CNRS 3503 GEIST, INSERM UMR s1094, Tropical Neuroepidemiology, University Hospital of Limoges, CHU Limoges, Preventive and Occupational Medicine, Limoges, France

${ }^{9}$ Emergency Department, University Hospital of Clermont-Ferrand (CHU), ClermontFerrand, France

Acknowledgements We express our sincere gratitude to Martine Lafaure, Gisèle Vernet, Françoise Chamoux, Béatrice Olagnier and Sarah De Saint Vincent who analysed the urine cytology. We also express our sincere gratitude to Professor Pierre Catilina who created the laboratory of occupational medicine to analyse urine cytology and follow occupation exposures.

Contributors FD and $A C$ contributed to the study design. FD and $A C$ were responsible for data collection. FD and $\mathrm{AM}$ were responsible of data processing. FD was responsible for the overall supervision. FD and LR wrote the first draft. GN, LF, $\mathrm{MD}-\mathrm{C}$ and FM revised the manuscript. All authors read, contributed towards and approved of the final manuscript.

Competing interests None declared.

Provenance and peer review Not commissioned; externally peer reviewed.

Data sharing statement № additional data are available.

Open Access This is an Open Access article distributed in accordance with the Creative Commons Attribution Non Commercial (CC BY-NC 4.0) license, which permits others to distribute, remix, adapt, build upon this work non-commercially, and license their derivative works on different terms, provided the original work is properly cited and the use is non-commercial. See: http://creativecommons.org/ licenses/by-nc/4.0/

(c) Article author(s) (or their employer(s) unless otherwise stated in the text of the article) 2017. All rights reserved. No commercial use is permitted unless otherwise expressly granted.

\section{REFERENCES}

1. Burger M, Catto JW, Dalbagni G, et al. Epidemiology and risk factors of urothelial bladder cancer. Eur Urol 2013;63:234-41.

2. Clin B, Pairon JC. Medical follow-up for workers exposed to bladder carcinogens: the French evidence-based and pragmatic statement. BMC Public Health 2014;14:1155.

3. Guillaume L, Guy L. [epidemiology of and risk factors for bladder cancer and for urothelial tumors]. Rev Prat 2014;64:1378-80.

4. Ross RK, Jones PA, Yu MC. Bladder cancer epidemiology and pathogenesis. Semin Oncol 1996;23:536-45.

5. Brown T, Slack R, Rushton L. Occupational cancer in Britain. Urinary tract cancers: bladder and kidney. Br J Cancer 2012;107(Suppl 1):S76-84.

6. Pira E, Piolatto G, Negri E, et al. Bladder cancer mortality of workers exposed to aromatic amines: a 58-year follow-up. J Natl Cancer Inst 2010;102:1096-9.

7. Golka K, Wiese A, Assennato G, et al. Occupational exposure and urological cancer. World J Urol 2004;21:382-91.
8. Carreón T, Hein MJ, Hanley KW, et al. Bladder cancer incidence among workers exposed to o-toluidine, aniline and nitrobenzene at a rubber chemical manufacturing plant. Occup Environ Med 2014:71:175-82.

9. Sellers C, Markowitz S. Reevaluating the carcinogenicity of orthotoluidine: a new conclusion and its implications. Regul Toxicol Pharmacol 1992:16:301-17.

10. Sorahan T. Bladder cancer risks in workers manufacturing chemicals for the rubber industry. Occup Med 2008;58:496-501.

11. Thériault G, Tremblay C, Cordier S, et al. Bladder cancer in the aluminium industry. Lancet 1984;1:947-50.

12. Mastrangelo G, Fadda E, Marzia V. Polycyclic aromatic hydrocarbons and cancer in man. Environ Health Perspect 1996;104:1166-70.

13. Rota M, Bosetti C, Boccia S, et al. Occupational exposures to polycyclic aromatic hydrocarbons and respiratory and urinary tract cancers: an updated systematic review and a meta-analysis to 2014 Arch Toxicol 2014;88:1479-90.

14. Reulen RC, Kellen E, Buntinx F, et al. A meta-analysis on the association between bladder cancer and occupation. Scand J Urol Nephrol Suppl 2008:64-78.

15. Cumberbatch MG, Windsor-Shellard B, Catto JW. The contemporary landscape of occupational bladder cancer within the United Kingdom: a meta-analysis of risks over the last 80 years. BJU Int 2017;119:100-9.

16. Kogevinas M, 't Mannetje A, Cordier S, et al. Occupation and bladder cancer among men in Western Europe. Cancer Causes Control 2003;14:907-14.

17. Calvert GM, Ward E, Schnorr TM, et al. Cancer risks among workers exposed to metalworking fluids: a systematic review. Am J Ind Med 1998;33:282-92.

18. Colt JS, Friesen MC, Stewart PA, et al. A case-control study of occupational exposure to metalworking fluids and bladder cancer risk among men. Occup Environ Med 2014;71:667-74.

19. Bosetti C, Boffetta P, La Vecchia C. Occupational exposures to polycyclic aromatic hydrocarbons, and respiratory and urinary tract cancers: a quantitative review to 2005. Ann Oncol 2007;18:431-46.

20. Bang KM. Epidemiology of occupational cancer. Occup Med 1996:11:467-85.

21. Olfert SM, Felknor SA, Delclos GL. An updated review of the literature: risk factors for bladder cancer with focus on occupational exposures. South Med J 2006;99:1256-63.

22. Conso F. [Occupational exposure and bladder cancer]. Rev Prat 2004;54:1665-70.

23. Andreassen BK, Myklebust TÅ, Haug ES. Crude mortality and loss of life expectancy of patients diagnosed with urothelial carcinoma of the urinary bladder in Norway. Scand J Urol 2017;51:38-43.

24. Anghel RM, Gales LN, Trifanescu OG. Outcome of urinary bladder cancer after combined therapies. J Med Life 2016;9:95-100.

25. Marsh GM, Callahan C, Pavlock D, et al. A protocol for bladder cancer screening and medical surveillance among high-risk groups: the Drake Health Registry experience. J Occup Med 1990;32:881-6.

26. Marsh GM, Cassidy LD. The Drake Health Registry Study: findings from fifteen years of continuous bladder cancer screening. Am J Ind Med 2003;43:142-8.

27. Presti JC, Weyrauch HM. Papanicolaou examination of urine in diagnosis of urinary cancer. I. As a test in mass screening. J Urol 1955;73:430-4.

28. Pesch B, Taeger D, Johnen G, et al. Screening for bladder cancer with urinary tumor markers in chemical workers with exposure to aromatic amines. Int Arch Occup Environ Health 2014:87:715-24.

29. Nutt $A$. Rubber work and cancer-past, present and perspectives. Scand J Work Environ Health 1983:9(Suppl 2):49-57.

30. Meigs JW, Marrett LD, Ulrich FU, et al. Bladder tumor incidence among workers exposed to benzidine: a thirty-year follow-up. J Natl Cancer Inst 1986;76:1-8.

31. Walker B, Gerber A. Occupational exposure to aromatic amines: benzidine and benzidine-based dyes. Natl Cancer Inst Monogr 1981:11-13.

32. Yamaguchi N, Tazaki H, Okubo T, et al. Periodic urine cytology surveillance of bladder tumor incidence in dyestuff workers. Am J Ind Med 1982;3:139-48.

33. Veys CA. Bladder tumours in rubber workers: a factory study 19461995. Occup Med 2004:54:322-9.

34. Highman WJ. Flat in situ carcinoma of the bladder: cytological examination of urine in diagnosis, follow up, and assessment of response to chemotherapy. J Clin Pathol 1988;41:540-6.

35. Piaton E, Advenier AS, Benaïm G, et al. [Atypical urothelial cells (AUC): A Bethesda-derived wording applicable to urinary cytopathology]. Ann Pathol 2011;31:11-17.

36. Siegel RL, Miller KD, Jemal A. Cancer statistics, 2015. CA Cancer J Clin 2015;65:5-29. 
37. Ploeg M, Aben KK, Kiemeney LA. The present and future burden of urinary bladder cancer in the world. World $\mathrm{J}$ Urol 2009;27:289-93.

38. Hadkhale K, Martinsen JI, Weiderpass E, et al. Occupational exposure to solvents and bladder cancer: A population-based case control study in Nordic countries. Int J Cancer 2017;140:1736-46.

39. Wilcox AN, Silverman DT, Friesen MC, et al. Smoking status, usual adult occupation, and risk of recurrent urothelial bladder carcinoma: data from The Cancer Genome Atlas (TCGA) Project. Cancer Causes Control 2016:27:1429-35.

40. Lokeshwar VB, Habuchi T, Grossman HB, et al. Bladder tumor markers beyond cytology: International Consensus Panel on bladder tumor markers. Urology 2005;66:35-63.

41. García Gómez M, Urbanos Garrido R, Castañeda López R, et al. [Direct health care costs of lung and bladder cancer attributable to work. Spain, 2008]. Rev Esp Salud Publica 2012;86:127-38. 